\title{
Family planning among female medical students: are their plans comparable to other professionals?
}

\author{
Juliana Araújo \\ (iD) Sthan Bacelar ${ }^{1}$ \\ Lisieux Eyer de Jesus²
}

1. Estudante de Medicina (residência), Faculdade de Medicina, Universidade Federal Fluminense, Rio de Janeiro, RJ, Brasil. 2. Cirurgião Pediátrico, Diretor do Departamento, Cirurgia Pediátrica, Univerdidade Federal Fluminense, Rio de Janeiro, RJ, Brasil.

http://dx.doi.org/10.1590/1806-9282.66.4.485

\section{SUMMARY}

INTRODUCTION: Late pregnancy is a problem among physicians, especially surgeons. This paper studies family planning among Medical Students (MS) and Law students (LS).

METHODS: A questionnaire was sent to all female MS and LS attending the two last years of University in the first semester of 2019. Data on age, family income, marital status, and family planning (age, planning for future pregnancies, timing, professional relationship or other issues, the ideal moment for a pregnancy, attitude towards eventual pregnancies, or maternity leave) were researched.

RESULTS: MS were significantly older than LS. A minority of women did not plan future pregnancies (10.6\% of MS and 16.4\% of LS), for markedly different reasons: $40 \%$ of the MS mentioned career plans, while for $70 \%$ of LS motherhood was not a personal project. The ages chosen for pregnancy also differed: MS tended to choose older ages. The most important priorities were financial planning and professional career for both groups, but specialization/post-graduation were only cited among MS. Both groups considered that the ideal moment for pregnancy was after professional consolidation in the job market. There were differences between MS that chose a surgical specialty and other MS.

DISCUSSION: MS tend to go through pregnancy late, especially students planning a surgical career. Professional issues are more influential over MS than LS. Medical educators and health managers must recognize there is a need to reconcile the medical career and motherhood as females represent $>50 \%$ of MS in Brasil.

KEYWORDS: Family planning. Reproductive health. Students, Medical. Women.

\section{INTRODUCTION}

Late pregnancy is a serious problem among physicians, especially surgeons. Obstetric problems, lower fertility, and frequent usage of in vitro fertilization are more frequent in this group ${ }^{1-4}$. This problem is getting more serious as the proportion of female students grows in Medical schools.
This paper aims to describe family planning among Medical Students (MS), as compared to Law students (LS). We hypothesize that MS enter Medical School at an older age than university students of other professions and postpone pregnancy till the completion of specialization/residency, due to the

DATE OF SUBMISSION: 22-Sep-2019

DATE OF ACCEPTANCE: $10-O c t-2019$

CORRESPONDING AUTHOR: Lisieux Eyer de Jesus

Rua Presidente Domiciano, 52, apt. 801, Boa Viagem, Rio de Janeiro, Brasil - 24210-270

Tel: +55 21 99985-9737

E-mail: lisieuxeyerdejesus@gmail.com 
length, degree of commitment and ethos in Medical School and Residency.

\section{METHODS}

A list of female students meeting the research criteria was obtained from the concerning offices of the Medical and Law schools of the Federal Fluminense University, a Public University in Rio de Janeiro, Brasil. A questionnaire was sent by e-mail to all female interns of the Medical School and all female students attending the last two years of Law School at the Federal Fluminense University, in the first semester of 2019, using a free web-based platform (Google Forms) to collect data, with immediate anonymization of the responses.

We opted for a quantitative research using a questionnaire planned for this specific purpose. The multiple choice, closed-ended questions involved epidemiological information (age, family income, marital status) and family planning (age, future planning of pregnancies, timing, professional relationship or other issues, ideal moment for pregnancy, attitude towards eventual pregnancies or maternity leave).

The questionnaires were sent by email three times, with a one-month interval, to each interviewee after the researchers presented the research project in faceto-face group encounters during meetings inserted into routine academic activities. There were no financial incentives. Each interviewee signed an informed consent concerning their participation in the research.

The chi-square test with Yates correction was used to analyze categorical data, considering $p$ values $<0.05$ as statistically valid. There was no funding for this research. The authors report no conflicts of interest. All authors reviewed the manuscript. SB and JA applied the questionnaire and compiled the data. LEJ analyzed data and wrote the manuscript.

\section{RESULTS}

$52.45 \%$ (96/183) of MS and 34.97\% (64/183) of LS responded our questionnaire. Five questionnaires were excluded due to inadequate filling (2 MS, 3 LS), leading to a final cohort of 94 MS and 61 LS.

MS were significantly older than LS (Table 1 and Figure 1). A total of $52.1 \%$ of MS were $\leq 25$ years-old, compared to $90.2 \%$ of $\mathrm{LS}(\mathrm{p}=0.006)$. Family income was similar among the two groups. Most students belong to Medium/Higher income brackets in Brasil
(78.7\% and $67.2 \%$ with family income $>4$ Brazilian minimum wages - approximately 1000 dollars among MS and LS, respectively, $\mathrm{p}=0.158$, Table 1). Being in a stable relationship or not was also comparable: 53 MS (56.4\%) were not and $41 \%$ were in stable relationships, as compared to 39 (63.9\%) and $21(34.4 \%)$ LS ( $p=0.371)$. One LS did not declare her status $(1.6 \%)$.

Most students (82 MS - 87.2\% - and 51 LS - 83.6\%) planned to have children in the future. Two MS were already mothers $(2.2 \%)$. One of them graduated first in another profession and studied Medicine as a second graduation, and the other had a son after an unplanned pregnancy during MS. One of them planned future pregnancies and the other did not (allegedly for professional reasons).

A similar minority of women who did not have children did not plan future pregnancies (10.6\% of MS and $16.4 \%$ of LS, $p=0.455$ ), but the reasons for their

TABLE 1. AGE DISTRIBUTION AND FAMILY INCOME OF MS AND LS (MS: MINIMUM SALARY IN BRASIL, APPROXIMATELY 250 DOLLARS IN THE FIRST SEMESTER OF 2019)

\begin{tabular}{l|l|l|l|l} 
AGES & MS & $\%$ & LS & $\%$ \\
\hline 20-22 years-old & 4 & 64,3 & 32 & 52,5 \\
\hline 23-25 years-old & 54 & 57,4 & 22 & 36,1 \\
\hline 26-28 years-old & 25 & 26,6 & 5 & 8,2 \\
\hline 19-31 years-old & 8 & 8,5 & 0 & 0 \\
\hline$>31$ years-old & 3 & 3,2 & 2 & 3,3 \\
\hline Family income & MS & $\%$ & LS & $\%$ \\
\hline 1-2 MS & 5 & 15,3 & 10 & 16,4 \\
\hline 3-4 MS & 15 & 16 & 10 & 16,4 \\
\hline 5-6 MS & 19 & 20,2 & 10 & 16,4 \\
\hline$>6$ MS & 55 & 58,5 & 31 & 50,8 \\
\hline
\end{tabular}

FIGURE 1. AGES OF MEDICAL AND LAW STUDENTS INTERVIEWED

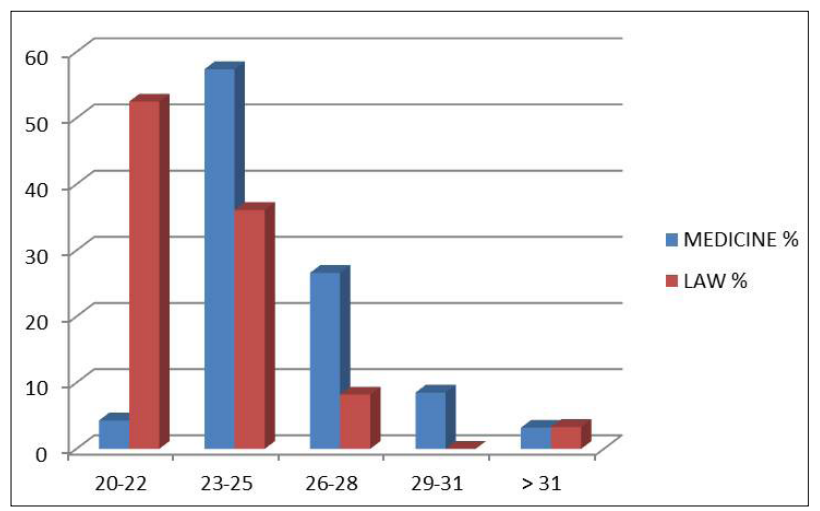


options were markedly different: while $40 \%$ of MS $(n=4)$ related their abdication to the career, $70 \%$ of $\mathrm{LS}$ declared that maternity was not a personal project (Table 2). The ideal ages to become a mother also differed among the two groups: MS tended to prefer older ages (Table 2). A total of $26.9 \%$ of LS believed the best age for having the first child would be $<30$ years-old, as compared to $9.5 \%$ of the MS ( $p=0.015)$.

We also studied the most important prominent factors for family planning. Some differences were notable (Figure 2). For both groups, the priorities were financial planning and professional career, but specialization/post-graduation were cited only among MS (16 citations). Family structure was mentioned as an important issue, as well as maternal age/maternal health (cited by approximately a third and half of the cohorts, respectively). Both groups considered that the ideal time for pregnancy was after consolidation as a professional in the job market (69.1\% of MS and 75.4\% of LS). Only $1 \mathrm{MS}$ would choose to start a family after graduation and before residency, while $11.5 \%(n=6)$ of the LS would choose this moment as ideal $(\mathrm{p}=0.031)$. Most students in both groups declared that familiar planning did not influence their professional choices (75.5\% and $83.6 \%$ of MS and LS, respectively, $\mathrm{p}=0.393$ ), and most would not consider postponing their academic career for a pregnancy $(69.1 \%$ and $82 \%$ of MS and LS, respectively, $\mathrm{p}=0.236$ ).

There were notable differences in a comparison between MS that would choose a surgical specialty (NSMS - 73 students, $77.8 \%$ ) and other MS (SMS - 21 students - 22.3\%). Ages, frequency of

TABLE 2. REASONS TO ABDICATE FROM A FUTURE MATERNITY PROJECT AND IDEAL AGE FOR PREGNANCY

\begin{tabular}{l|l|l|l|l}
\hline \multicolumn{6}{l}{ REASONS TO ABDICATE FROM FUTURE MATERNITY } \\
\hline REASON & MS & $\%$ & LS & $\%$ \\
\hline CAREER & 4 & 40 & 2 & 20 \\
\hline $\begin{array}{l}\text { NOT A PERSONAL } \\
\text { PROJECT/WISH }\end{array}$ & 4 & 40 & 7 & 70 \\
\hline DID NOT ANSWER & 2 & 20 & 1 & 10 \\
\hline TOTAL & 10 & 100 & 10 & 100 \\
\hline \begin{tabular}{l|l|l|l} 
IDEAL AGE FOR PREGNANCY \\
AGES
\end{tabular} & MS & $\%$ & LS & $\%$ \\
\hline 20-24 years-old & 0 & 0 & 1 & 1,6 \\
\hline 25-29 years-old & 8 & 8,5 & 13 & 21,3 \\
\hline 30-34 years-old & 65 & 69,1 & 31 & 50,8 \\
\hline >34 years-old & 11 & 11,7 & 7 & 11,5 \\
\hline Did not respond & 10 & 10,6 & 9 & 14,8 \\
\hline TOTAL & 94 & 100 & 61 & 100 \\
\hline
\end{tabular}

stable relationships, and family income were similar between the two groups, despite a tendency of SMS for a bimodal distribution of household incomes.

The proportion of SMS and NSMS desiring future pregnancies was similar (90.3\% and 85\%, respectively), but only NSMS $(11 \%, n=8)$ would choose to have children when aged $<30$ years-old. Concerning the reasons influencing familiar planning, there were notable differences among NSMS and SMS (Figure 2). Career and specialization were much more cited as important by SMS ( $p=0.053$ and $p=0.001$, respectively). Surprisingly, both cohorts denied family planning would affect professional choices in similar proportions $(p=0.831)$. Family structure, in contrast, was much more important for NSMS.

\section{DISCUSSION}

Our paper suffers from the usual limitations of research based on mailed questionnaires. Survey fatigue and lack of direct involvement/personal interest with the research may justify the lower ratio of responses from LS. Notably, electronic questionnaires have been extensively used to explore opinions of

FIGURE 2. FACTORS INFLUENCING FAMILY PLANNING AMONG MEDICAL AND LAW STUDENTS

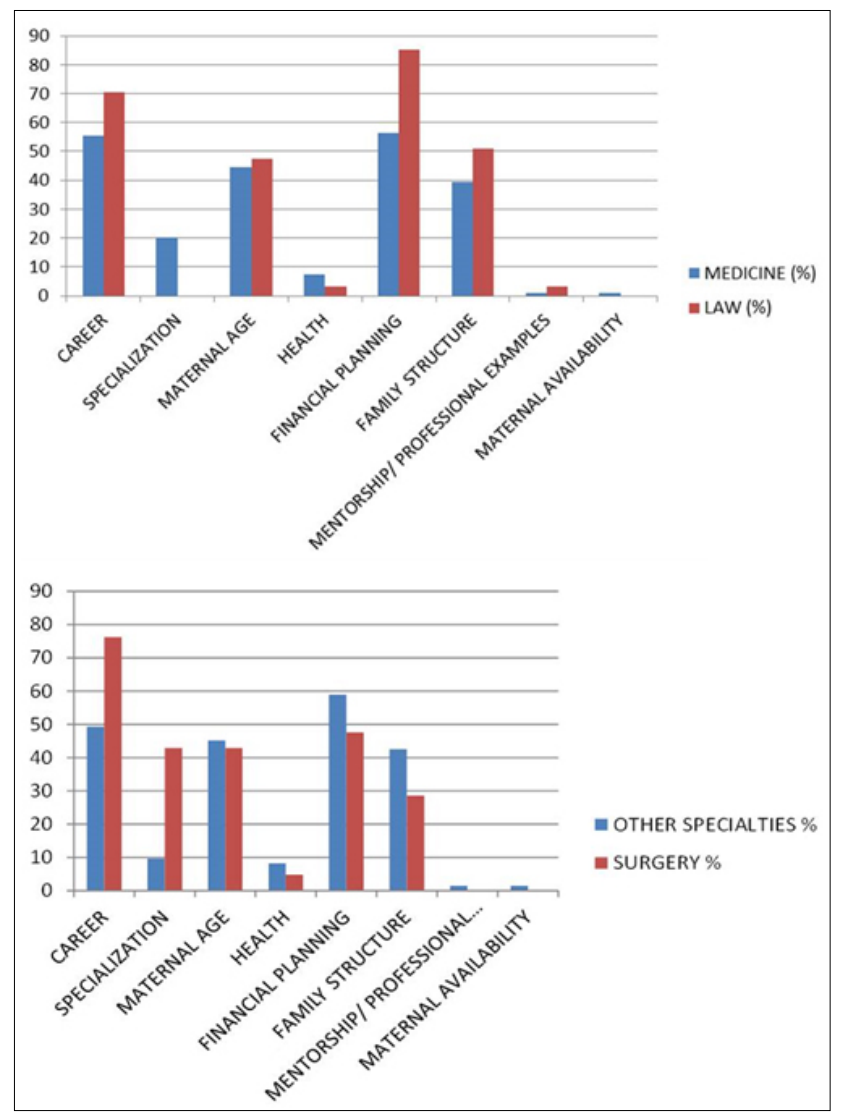


medical professionals or students in many fields, particularly concerning quality of life and professional choices, including most of the references cited in our research. The usage of a non-validated questionnaire is also a limitation, but we were unable to find a similar research project for comparison. Our questionnaire was exhaustively discussed and modified by our team before being considered satisfactory for our purposes. Standardization and anonymity were guaranteed. Face to face exposition of our research project was done previously to the delivery of the questionnaire to clarify any doubts/interpretation problems and to present the project.

This research project was proposed by MS in mentorship meetings with a female Professor, in the context of discussing their worries about family planning and difficulties in accepting maternity and maternity leave in the ethos of Medicine, which frequently lead female MS to find there was a contradiction between pregnancy and motherhood and a career in medicine. We hypothesized that those dilemmas, however common among females in contemporaneous societies, are worse for Physicians, as compared to other professions. We were unable to find published data about Brazilian physicians/MS, but our hypotheses were confirmed in foreign studies. For 77.6 of American MS their career choice was a definitive influence over family planning: $1 / 4$ postponed pregnancies and $7.5 \%$ opted against parenthood exclusively because they were $\mathrm{MS}^{5}$. Another research among emergency doctors (56\% women), also in the USA, confirmed that institutional policies concerning parenthood were unsatisfactory for $1 / 3$ of female professionals, who desired clearer policies, longer parental leave, better financial security, better planned work shifts for substitutes during parental leave and breastfeeding support ${ }^{6}$. In another paper, 6 and $16 \%$ of female and male thoracic surgeons, respectively, admitted that a pregnancy would be interpreted as something negative in the professional environment $^{3}$. This was confirmed by another research, demonstrating that even other female residents considered a colleague's pregnancy disruptive ${ }^{7}$, both confirming that medical ethos can be a negative factor towards pregnant female professionals. The low priority of family planning in medicine was demonstrated in a recent research involving 127 medical schools in the USA: only $34 \%$ have protocols covering pregnancy, and $2 / 3$ offer only 6-8 weeks of parental leave e $^{8,9}$.

An important issue, confirmed in the literature, is the option for later pregnancies that predominates among MS: more than 90\% intended to get pregnant in their 4 th decade of life and $>10 \%$ after 34 years of age. Late pregnancy planning was prominent amonsgt SMS as compared to NSMS, and is possibly related to greater demands for residency/specialization in surgical specialties and the professional environment and competition in Surgical specialties. The influence of Residency over family plans is confirmed by other researchers: $70 \%$ of MS judged that the best moment for a pregnancy was after Residency ${ }^{9}$.

Late pregnancy has negative consequences on fertility and obstetric health. Female surgeons, urologists, and orthopedists generally postponed pregnancies with higher frequencies of obstetric complications, infertility, and use of in vitro fertilization methods ${ }^{1-3}$. Among female urologists, pregnancies occurred 7-8 years later and the need for in vitro fertilization was 10 times more common, as compared to the general population ${ }^{4}$.

LS were chosen as a comparative cohort to guarantee reasonable similarity: both cohorts would graduate in the following year and both groups come from similar social strata in Brazilian society (predominance of high/medium class), which was confirmed in our research.

LS were younger than MS. This is probably due to late admission in Medical School and signals a difference between professions. In Brasil, yearly admission exams to Public University Courses are mandatory and extremely competitive to acess Medical School (89.41 candidates/spot in 2018, compared to 21.67 candadates/spot in Law School) $)^{10}$. Students frequently need to pass multiple exams to access Medical Schools. Also, graduation in Medicine is longer than in Law (6 and 4 years, respectively). We did not detect differences between the two groups that seemed to be attributed to age differences, including being or not in a stable relationship.

A small proportion of women did not plan a future pregnancy in both cohorts (12.8\% among MS and 16.4\% among LS). This ratio is similar to the general population of females that opt not to become mothers in Brasil (14\%, according to the Brazilian Institute of Geography and Statistics - IBGE) ${ }^{11}$. However, it is possible that the proportion of LS opting against motherhood changes in time, due to their younger age. A novel finding in our research is that LS opted against future pregnancies for personal reasons, as Brazilian women in general, but professional reasons were disproportionately high amongst MS (40\%), especially SMS. 
Financial planning and professional career were the most important factors relating to family planning for both groups, reflecting the reality of medium and high social class in Brasil. However, for MS, Residency and specialization assumed a prominent position, while amongst LS post-graduation was not influential. Maternal age/maternal health worries, cited by half of the students in both groups, was an important consideration, probably related to late pregnancy plans.

Surprisingly, both cohorts, including SMS, denied family planning to affect professional choices in similar proportions. Family structure, in contrast, was much more important for NSMS and LS than for SMS. We could not explain this finding; it may be directly related to the "type A" personality commonly attributed to female surgeons.

Most students would not consider postponing their academic career for a pregnancy, suggesting that this option, cited in the literature as a possible strategy to avoid late pregnancies among female doctors would not be well accepted in Brasil. This has also been demonstrated in the USA, where 13/18 students after pregnancy or parenthood (15\% of medical students) would extend parental leave, but only if it did not imply to postpone graduation ${ }^{12}$.

Gender inequality is a fact in Medicine, although more than half of the students that graduate nowadays from medical school are female in most countries ${ }^{13}$. The unavailability of female mentors, despite being considered an important problem for medical educators, has been denied as influential or important by female medical students in many research papers ${ }^{13}$. This was also seen in our research: the absence of female professional examples, including their life experience with pregnancy was not cited as influential over future familial planning.

A recent paper about career satisfaction among Surgical Residents in USA that had children (mean age 30.5 years-old) showed that they considered leaving career or revisiting their career choices because of difficulties in reconciling pregnancy and motherhood with surgical training and because of their perception of stigma during pregnancy. Many would advise female students against surgery as a career for women ${ }^{14,15}$. Other attest that $2 / 3$ of the female surgeons opted for pregnancy during training, but $85.6 \%$, while concerned that their work schedule would adversely affect their pregnancy, maintained their work schedules throughout pregnancy. Most resented the absence of institutional support for pregnancy, maternity leave, and lactation ${ }^{15}$. Differences between male and female Surgical Residents and Surgeons have been demonstrated: while $64 \%$ and $95 \%$ of the males had children, only 15 and $40 \%$ of the females did so, during and after residency. Most women considered that part-time work would be a solution to reconcile parenting and the surgical practice ${ }^{16}$.

\section{CONCLUSION}

MS choices concerning family planning are directly related to late pregnancy, specially among students who plan a surgical career, and give rise to obstetric and fetal health concerns, spontaneous infertility, and need for in vitro fertilization. Professional issues are more influential over career planning among MS than among LS. Medical educators and health managers must recognize there is a need to reconcile the Medical career and motherhood, especially among surgical professionals, as the proportion of females among MS and physicians is over 50\% in most countries, including in Brasil.

\section{Author's contribution}

Sthan Bacelar ORCID - Lisieux Eyer de Jesus - Planing of the study, development of the original concept;

Juliana Araújo - Design of the questionnaire;

Sthan Bacelar - Data aquisition, and tabulation;

Juliana Araújo - Lisieux Eyer de Jesus - Interpretation of the data and statistical evaluation;

Juliana Araújo - Sthan Bacelar - Lisieux Eyer de Jesus - Manuscript drafting;

Juliana Araújo - Sthan Bacelar - Lisieux Eyer de Jesus - Final review of the manuscript. 


\section{SUMMARY}

INTRODUÇÃO: A gravidez tardia é um problema entre médicas, principalmente entre cirurgiãs. Este trabalho analisou o planeamento familiar de estudantes de medicina (MS) e estudantes de Direito (LS).

METODOLOGIA: Um questionário foi enviado para todas as estudantes de medicina e direito cursando os dois últimos anos do curso universitário no primeiro semestre de 2019. Idade, renda familiar, estado civil e planejamento familiar (idade, planejamento de futuras gestações, relacionamento profissional ou com outras questões, momento ideal para uma gestação, atitude em relação a uma eventual gravidez ou licença maternidade) foram investigados.

RESULTADOS: As MS eram significativamente mais velhas que as LS. Uma minoria das mulheres não planeja futuras gestações (10,6\% das MS e 16,4\% das LS), por razões distintas: $40 \%$ das MS mencionaram planos profissionais, enquanto para $70 \%$ das LS a maternidade não era um projeto pessoal. As idades escolhidas para a gravidez também foram diferentes: MS, em geral, optaram por idades mais avançadas. As prioridades mais mencionadas foram o planeamento financeiro e a carreira em ambos os grupos, mas especialização/ pós-graduação só foram citadas entre as MS. Ambos os grupos consideraram que o momento ideal para uma gestação seria após a consolidação profissional no mercado de trabalho. Houve diferenças entre as MS que escolheram uma especialidade cirúrgica e outras MS.

DISCUSSÃO: MS tem uma tendência a gestações tardias, especialmente as que planejam uma carreira cirúrgica. Questões profissionais têm mais influência entre as MS do que entre as LS. Educadores e gestores da área médica devem reconhecer de que há uma necessidade de conciliar a carreira médica e a maternidade, já que as mulheres representam > 50\% dos estudantes de medicina no Brasil.

PALAVRAS-CHAVE: Planejamento familiar. Saúde reprodutiva. Estudantes de Medicina. Mulheres.

\section{REFERENCES}

1. Phillips EA, Nimeh T, Braga |, Lerner LB. Does a surgical career affect a woman's childbearing and fertility? A report on pregnancy and fertility trends among female surgeons. I Am Coll Surg. 2014;219(5):944-50.

2. Hamilton AR, Tyson MD, Braga JA, Lerner LB. Childnearing and pregnancy characteristics of female orthopedic surgeons. J Bone Joint Surg Am. 2012;94(11):e77.

3. Pham DT, Stephens EH, Antonoff MB, Colson YL, Dildy GA, Gaur P, et al. Birth trends and factors affecting childbearing among thoracic surgeons. Ann Thorac Surg. 2014;98(3):890-5.

4. Lerner LB, Stolzmann KL, Gulla VD. Birth trends and pregnancy complications among women urologists. J Am Coll Surg. 2009;208(2):293-7.

5. Khadjooi K, Scott $P$, Jones $L$. What is the impact of pregnancy and parenthood on studying medicine? Exploring attitudes and experiences of medical students. J R Coll Physicians Edinb. 2012;42(2):106-10.

6. MacVane CZ, Fix ML, Strout TD, Zimmerman KD, Bloch RB, Hein CL. Congratulations, you're pregnant! now about your shifts...: the state of maternity leave attitudes and culture in EM. West J Emerg Med. 2017;18(5):800-10.

7. Turner PL, Lumpkins K, Gabre J, Lin MJ, Liu X, Terrin M. Pregnancy among women surgeons: trends over time. Arch Surg. 2012;147(5):474-9.

8. Grisso JA, Hansen L, Zelling I, Bickel J, Eisenberg JM. Parental leave policies for faculty in U.S. medical schools. Ann Intern Med. 1991;114(1):43-5.
9. Sinal S, Weavil P, Camp MG. Survey of women physicians on issues relating to pregnancy during a medical career. J Med Educ. 1988;63(7):531-8.

10. Universidade Federal Fluminense. Inscritos e Relação Candidato Vaga: SiSU 2018-2a Edição. [cited 2019 Aug 06]. Available from: http://www.coseac. uff.br/2018/2018-2/CV-2018-2.htm

11. IBGE. Estatísticas de gênero: uma análise dos resultados do censo demográfico 2010. [cited 2019 Aug 06]. Available from: https:// biblioteca. ibge.gov.br/visualizacao/livros/liv88941.pdf

12. Bye EM, Brisck BW, Reuter SD, Hansen KA, Nettleman MD. Pregnancy and parenthood during medical school. S D Med. 2017;70(12):551-5.

13. Dixon A, Silva NA, Sotayo A, Mazzola CA. Female medical student retention in neurosurgery: a multifaceted approach. World Neurosurg. 2019;122:245-51.

14. Rangel EL, Lyu H, Haider AH, Castillo-Angelles M, Doherty GM, Smink DS. Factors associated with residency and career dissatisfaction in childbearing surgical residents. JAMA Surg. 2018;153(11):1004-11.

15. Rangel EL, Smink DS, Castillo-Angeles M, KwaKye G, Changala M, Haider $\mathrm{AH}$, et al. Pregnancy and motherhood during surgical training. JAMA Surg. 2018;153(7):644-52.

16. Mayer KL, Ho HS, Goodnight Jr JE. Childbearing and child care in surgery. Arch Surg. 2001;136(6):649-55. 